\author{
EVALUATION OF CHEMICAL COMPOSITION \\ OF ESSENTIAL OILS DERIVED \\ FROM DIFFERENT Pelargonium SPECIES LEAVES
}

\author{
OCENA SKŁADU CHEMICZNEGO OLEJKÓW ETERYCZNYCH \\ POZYSKANYCH Z LIŚCI RÓŻNYCH GATUNKÓW ROŚLIN \\ Z RODZAJU Pelargonium
}

\begin{abstract}
Plants have been used for their aromatic and medicinal purposes for centuries. The genus Pelargonium contains about 250-280 species and cultivated around the world for the production of essential oils and absolutes. Pelargonium species are remarkable for their odour diversity, from fresh, lemon and minty scent, through floral, rose, fruity up to spicy and camphoreous smell as well as many health beneficial properties, that is why their essential oils are widely used in perfume, cosmetic, food and pharmaceutical industries. The aim of this study was to determine variability in populations of Pelargonium genus by evaluating their differences in quantitative and qualitative essential oils compositions. This study determined that of all the examined essential oil, the one of $P$. graveolens indoor cultivar has the closest $\mathrm{C}: \mathrm{G}$ ratio (1.16) which makes it a very valuable product. In comparison with available literature, beside the geographical region of plant growth, all essential oils from $P$. graveolens contain a diverse range of compounds, nevertheless, in every single one, geraniol and citronellol are present in the most significant fraction of the total oil. The examined $P$. roseum essential oil was characterized by the highest level of citronellol (44.62\% of total oil), but it can be due to the chemical reactions (conversion geraniol into citronellol) occurring in stored product.
\end{abstract}

Keywords: citronellol, geraniol, essential oil, $P$. graveolens, $P$. odoratissimum, $P$. roseum

\title{
Introduction
}

For centuries plants and their extracts have been used for aromatic and medicinal purposes. Essential oils are an ingredient of perfumes, cosmetics, food and pharmaceuticals. Pelargonium species, because of their differential properties and odour diversity are commonly used for essential oil production.

In this study, chemical compositions of different Pelargonium species essential oils were compared. A great emphasis was put on dominant components of examined mixtures. Because studied essential oils were derived from plants that had grown in different environmental conditions, gas chromatographic - mass spectral analysis was used to

\footnotetext{
${ }^{1}$ Institute of Environmental Engineering and Biotechnology, University of Opole, ul. kard. B. Kominka 6a, 45-035 Opole, Poland, phone +48 774016050

*Corresponding author: adriana.szutt@uni.opole.pl
} 
determine if the major components of pelargonium essential oils are representative for the whole genus regardless cultivation conditions.

\section{Essential oils}

Plants have been used for their aromatic and medicinal purposes for centuries. With the world development and the appearance of many illnesses of the modern civilization, in recent years there has been considerable interest in bioactive agents, especially antimicrobial and antioxidant substances from natural sources, mainly in essential oils, also called volatile odoriferous/volatile oils [1-6]. Essential oils are described by International Organization for Standardization (ISO) as "products obtained from vegetable raw material, either by distillation with water or steam, or from the epicarp of citrus fruits by mechanical process, or by dry distillation" [7]. They are chemically complex mixtures, often containing from only a few up to several hundred of single substances. They are aromatic oily liquids extracted from different parts of plant, mainly the non woody ones, for example, flowers, leaves, peels, buds or seeds, but also cells glands and ducts in, which the essential oils are found, are located in woody parts, such as bark or roots $[5,8]$. Volatile oils are widely used in different industries, for example as natural additives in foods and foodstuff packaging materials to prevent them from the oxidative damage and inflammatory conditions, they are added as a natural preservatives or fragrances in majority of cosmetics. Natural antioxidants contained in volatile odoriferous inhibit also aging and prevent inflammatory diseases. Moreover, essential oils replace synthetic substances in the nutritional, pharmaceutical, and agricultural fields due to their reported antiviral, nematicidal, antifungal and insecticidal properties. For medical purposes they need to comply with national or international Pharmacopoeia [3, 5, 8-10]. Essential oils vary in compounds composition, properties, odour, flavour as well as in colour. Depending on plant health, growth stage, habitat and harvest time of starting material, the odoriferous oils are composed of different ratio of lipophilic and highly volatile secondary plant metabolites. Their dominant constituents are terpenes (mono- and sesquiterpenes), aromatic compounds and terpenoids [5, 9]. Essential oils can be obtained by various methods, from which steam distillation has been traditionally applied. Another methods are: extraction with fat and solvents or recently developed techniques, such as extraction with liquefied $\mathrm{CO}_{2}$ gas and solvent free microwave extraction (SFME) [5, 8].

\section{Pelargonium spp. essential oils}

The genus Pelargonium is one of the seven genera of the Geraniaceae family (Geranium, Pelargonium, Erodium, Monsonia, Hypseocharis, Rhynchotheca and Sarcocaulon). This genus contains about 250-280 species and include a range of variation in floral morphologies and life forms [11-13]. Hybrids of Pelargonium are cultivated around the world for the production of essential oils and absolutes, but original regions for Pelargonium genus are South Africa and nearby countries. It's cultivars grow mainly in Reunion Island, China, Egypt, Algeria and Morocco. While China and Egypt are the major producers of pelargonium volatile oils, the Bourbon geranium from Reunion Island is considered as one of the highest quality essential oils [11-16]. The oils are characterized by high levels of citronellol, geraniol, isomenthone, linalool accompanied by wide range of esters, such as citronellyl formate, geranyl formate, geranyl acetate, geranyl propionate and sesquiterpenes, of which 10-epi- $\gamma$-eudesmol and guaia-6,9-diene are the most important $[16,17]$. Very valuable in high grade perfume chemical aromas obtained from Geraniaceae 
family is rhodinol (a mixture of geraniol, citronellol and other alcohols) [18]. Pelargonium species are remarkable for their odour diversity, from fresh, lemon and minty scent, through floral, rose, fruity up to spicy and camphoreous smell. The most often commercially used plant in described genus are: $P$. capitatum, $P$. graveolens, $P$. odoratissium and $P$. radens [12].

$P$. graveolens is an aromatic and hairy shrub, erect up to $1-1.3 \mathrm{~m}$ tall and $1 \mathrm{~m}$ spread with soft to the touch and carved leaves, and usually small, pink flowers. It's essential oil yield is high and varies from 0.1-0.9 \% v/w [13, 19]. The oil is obtained from leaves, flowers and stalks [21]. Studies show that variety of factors, such as cultivar, method of oil distillation, distilled part of the plant, as well as age of this material, essential oil storage, location of growing and seasonal changes (temperature, light intensity) of the area, also season and time of harvesting, influence the final essential oil composition of rose-scented geranium $[17,22]$. Essential oil from $P$. graveolens is very valuable not only for perfumery, food and beverages industry, but it has also a variety of healing properties. It has an antidepressant, anticancer and hemostatic effect, moreover, it regulates bloodstream and stimulates the adrenal glands. This oil has been found to stimulate lymphatic system which in combination with diuretic properties is excellent in the fight against cellulite and fluid retention in the body. Pelargonium essential oil helps with heavy menstrual flows or hemorrhoids and many other diseases $[19,20]$. Major volatiles in $P$. graveolens essential oil composition are citronellol, geraniol, linalool, citronellyl formate, methone, isomenthone and nerol [21, 22].

Pelargonium roseum is indigenous to Southern Africa and was introduced in Europe in the $18^{\text {th }}$ century. Due to its rose odour, it is widely grown as an ornamental plant almost all over the world. P. roseum has woody, straight and branched stem that can reach heights of $120 \mathrm{~cm}$. The leaves are covered in short, rough trichomes which give the plant characteristic rose smell [23, 24].

$P$. odoratissimum leaves are frequently used not only as a flavouring, an insect repellent, but also in perfumery or aromatherapy in throat infections and gastrointestinal diseases treatments [10]. Another studies show that essential oil from P. oddoratissimum leaves has antibacterial and spasmolytic properties. Its bioactivity and effectiveness against Staphyloccocus aureus, S. Epidermis, Proteus vulgaris and Bacillus cereus is proven to be due to the presence of methyl eugenol [25].

The aim of this study was to determine variability in populations of Pelargonium genus by evaluating their differences in quantitative and qualitative essential oils compositions. It is the first work where the chemical compositions of oils derived from P. roseum, P. graveolens and P. odoratissimum are compared.

\section{Experimental}

\section{Materials and methods}

Three commercial pelargonium essential oils: P. graveolens from Etja, Poland, $P$. roseum from Aromatika, Ukraine and $P$. odoratissimum from Avicenna oil, Poland were purchased from the manufacturers in quantity of 3 of each oil, and their chemical compositions were determined by gas chromatography - mass spectrometry.

Also an essential oil compounds from freshly harvested leaves of $P$. graveolens indoor cultivation were analysed. $100 \mathrm{~g}$ of leaves from one-year old odorous plants were harvested in November. Material was collected from twenty pelargoniums and the leaves were 
randomly picked from different plants heights, then cut into small pieces and immediately transferred to round bottom flask of the Deryng apparatus. Water was added till the plant material was completely submerged and then subjected to hydrodistillation. The material has been distilled for 3 hours after reaching the boiling point. The chemical composition of the obtained essential oil was determined by gas chromatography - mass spectrometry as well. Also a citronellol/geraniol ratio (C:G) in studied Pelargonium species essential oils was calculated.

\section{Gas Chromatographic-Mass Spectral Analysis}

The analyses were performed using a Varian Chrompack CP-3800 gas chromatograph equipped with $4000 \mathrm{GC} / \mathrm{MS} / \mathrm{MS}$ system and flame ionization detector (FID). The carrier gas was helium with a flow rate of $1.0 \mathrm{~cm}^{3} / \mathrm{min}$. The $\mathrm{GC}$ oven temperature program was used as follows: $50{ }^{\circ} \mathrm{C}$ initial temperature hold for $1 \mathrm{~min}$, increased at $4{ }^{\circ} \mathrm{C} / \mathrm{min}$ to $240{ }^{\circ} \mathrm{C}$ and hold for $10 \mathrm{~min}$. A $1 \% \mathrm{w} / \mathrm{v}$ solution of the sample in hexane was prepared and $1 \mathrm{~mm}^{3}$ was injected using a splitless injection technique. The split ratio 1:50, scan time $0.8 \mathrm{~s}$; mass range $40-1000 \mathrm{~m} / \mathrm{z}$ (mass-to-charge ratio). Identification of components in the oils was based on GC retention indices relative to $n$-alkanes and computer matching with the Nits Library and Adams Library.

\section{Phytochemical similarity of studied essential oils}

To assess similarity in the oils composition a dendrogram was constructed. In Figure 1 structure of the dendrogram is presented. Among the compounds listed in Table 1. The following were taken for dissimilarity matrix construction: 1-3, 5, 9, 11, 12, 18, 24-26, 29 and 30. Prior to calculations of euclidean distance, concentrations were recalculated using centered logratio (clr) transformation. This transformation ensures appropriate sample space for distance calculation between pairs of points representing different oils [26]. The "complete" agglomeration method in function "hclust" that performs a hierarchical cluster analysis using a set of dissimilarities, provided in $\mathrm{R}$ language was applied for dendrogram construction [27]. Also a similarity between relative compounds' concentration in the studied plants was assessed.

\section{Results}

\section{Gas Chromatographic-Mass Spectral Analysis}

There have been determined the presence of ninety-seven compounds in the commercial $P$. graveolens essential oil, accounting for $99.04 \%$ of the total oil. A component of the largest amount in this EO (essential oil) was citronellol $(22.28 \%)$, followed by geraniol $(15.50 \%)$, geranyl acetate $(13.13 \%)$, limonene $(9.27 \%)$, phenyl ethyl alcohol $(5.93 \%)$ and linalool $(5.59 \%)$. This commercial essential oil was the only one from all examined oils in which a trace of isomenthone was not detected. In $P$. odoratissimum essential oil, ninety-eight compounds were identified representing $99.34 \%$ of the total oil. As in the previous oil, a significant amount of citronellol $(29.77 \%)$ was determined. Another dominant components were citronellyl formate $(9.22 \%)$, geraniol $(6.51 \%)$, isomenthone $(3.34 \%)$, linalool $(2.45 \%)$, menthone $(2.23 \%)$. There was a presence of seventy-six compounds in the essential oil from $P$. roseum determined, accounting for $99.32 \%$ of the total oil. The components identified as principal were citronellol (44.62\%), citronellyl formate (14.42\%), geraniol $(10.73 \%)$, linalool $(5.39 \%)$, 
menthone $(3.04 \%)$, isomenthone $(0.89 \%)$ and limonene $(0.35 \%)$. The essential oil from indoor cultivar of $P$. graveolens was characterized by a light green colour and had a strong odour which in that moment was not very similar to the smell of freshly cut leaves. In this extract, seventy-three compounds were identified representing $99.58 \%$ of the total oil. Essential oil extraction was performed on leaves, as the preliminary experiments showed that the hydrodistillation of stems and petiole was inefficient. The most abundant components in this sample were citronellol $(26.62 \%)$ and geraniol $(22.92 \%)$. Another significant compounds were linalool $(6.37 \%)$, geranyl tiglate $(4.37 \%)$, isomenthone $(3.39 \%)$ and limonene $(0.10 \%)$. Unlike in the previous essential oils, only trace amount of citronellyl formate was detected and no presence of geranyl formate was determined. The major components, which content was bigger than $1 \%$, constituted from $82.35 \%$ in $P$. odoratissimum, up to $92.33 \%$ in $P$. graveolens of the total oil. This chemical analysis of studied essential oils are presented in Table 1.

As the result of chemical analysis of studied essential oils show, citronellol and geraniol were identified in all EO, but in different ratio. The most preferable ratio $(\mathrm{C}: \mathrm{G})$ is 1 , because as the literature data shows that pelargonium essential oil is of the best quality, which is very important for perfumery, flavouring and cosmetics industries. In this study the closest ratio was examined in indoor cultivar of $P$. graveolens (1.16). Also the $(\mathrm{C}: \mathrm{G})$ ratio in EO from commercial $P$. graveolens was similar (1.44), while in other essential oils this parameter was very different. In $P$. odoratissimum EO it was 4.57 and in $P$. roseum, the ratio was 4.16 .

Table 1

Chemical composition of commercial essential oils of $P$. graveolens, $P$. odoratissimum, $P$. roseum and indoor cultivar of $P$. graveolens which content was bigger than $1 \%$

\begin{tabular}{|c|c|c|c|c|c|c|c|c|c|}
\hline \multirow{2}{*}{ Serial No. } & \multirow{2}{*}{ Component } & \multicolumn{2}{|c|}{$\begin{array}{c}\text { Indoor cultivar of } \\
\text { P. graveolens }\end{array}$} & \multicolumn{2}{|c|}{$P$. graveolens } & \multicolumn{2}{|c|}{ P. odoratissimum } & \multicolumn{2}{|c|}{ P. roseum } \\
\hline & & {$[\%]^{*}$} & RI & {$[\%]^{*}$} & RI & {$[\%]^{*}$} & RI & {$[\%]^{*}$} & RI \\
\hline 1 & Limonene & 0.10 & 1027 & 9.27 & 1028 & 0.15 & 1028 & 0.35 & 1027 \\
\hline 2 & Linalool & 6.37 & 1092 & 5.59 & 1092 & 2.45 & 1092 & 5.39 & 1091 \\
\hline 3 & Rose oxide & 0.06 & 1101 & 0.12 & 1101 & 1.63 & 1011 & 1.86 & 1100 \\
\hline 4 & Phenylethyl alcohol & - & - & 5.93 & 1105 & 1.96 & 1105 & - & - \\
\hline 5 & Menthone & 0.07 & 1153 & 0.17 & 1153 & 2.23 & 1154 & 3.04 & 1153 \\
\hline 6 & Isoborneol & - & - & 1.32 & 1162 & - & - & - & - \\
\hline 7 & Borneol & - & - & 1.79 & 1172 & - & - & - & - \\
\hline 8 & Isomenthone & 3.39 & 1164 & - & 1190 & 3.34 & 1164 & 0.89 & 1163 \\
\hline 9 & $\alpha$-Terpineol & 0.31 & 1198 & 2.38 & 1198 & 0.31 & 1198 & 0.82 & 1197 \\
\hline 10 & $\begin{array}{l}\text { Endo-Fenchyl } \\
\text { acetate }\end{array}$ & - & - & 8.57 & 1229 & 1.20 & 1229 & - & - \\
\hline 11 & Citronellol & 26.62 & 1234 & 22.28 & 1233 & 29.77 & 1234 & 44.62 & 1234 \\
\hline 12 & Geraniol & 22.92 & 1259 & 15.50 & 1257 & 6.51 & 1256 & 10.73 & 1256 \\
\hline 13 & Citronellyl formate & tr. & 1278 & 1.67 & 1277 & 9.22 & 1279 & 14.42 & 1278 \\
\hline 14 & Geranyl formate & - & - & 0.59 & 1303 & 1.43 & 1303 & 2.37 & 1303 \\
\hline 15 & Geranyl acetate & - & - & 13.13 & 1382 & 0.80 & 1381 & 0.55 & 1381 \\
\hline 16 & $\beta$-Bourbonene & tr. & 1386 & 0.09 & 1386 & 1.28 & 1386 & 0.17 & 1386 \\
\hline 17 & $\begin{array}{l}\text { Phenyl ethyl } \\
\text { isobutanoate }\end{array}$ & 0.10 & 1396 & tr. & 1396 & 1.04 & 1396 & - & - \\
\hline 18 & (e)-Caryophyllene & 0.23 & 1425 & 0.14 & 1425 & 1.64 & 1425 & 1.92 & 1424 \\
\hline 19 & $\begin{array}{l}\text { Citronellyl } \\
\text { propanoate }\end{array}$ & - & - & - & - & - & - & 3.05 & 1447 \\
\hline
\end{tabular}




\begin{tabular}{|c|c|c|c|c|c|c|c|c|c|}
\hline \multirow[t]{2}{*}{ Serial No. } & \multirow[t]{2}{*}{ Component } & \multicolumn{2}{|c|}{$\begin{array}{c}\text { Indoor cultivar of } \\
P \text {. graveolens }\end{array}$} & \multicolumn{2}{|c|}{ P. graveolens } & \multicolumn{2}{|c|}{ P. odoratissimum } & \multicolumn{2}{|c|}{ P. roseum } \\
\hline & & {$[\%]^{*}$} & RI & {$[\%]^{*}$} & RI & {$[\%]^{*}$} & RI & {$[\%]^{*}$} & RI \\
\hline 20 & $\begin{array}{c}\text { Allo- } \\
\text { Aromadendrene }\end{array}$ & 9.92 & 1451 & 0.86 & 1450 & 8.08 & 1451 & - & - \\
\hline 21 & Geranyl propanoate & - & - & tr. & 1481 & - & - & 1.05 & 1481 \\
\hline 22 & Neryl isobutanoate & 1.70 & 1482 & - & - & 0.54 & 1482 & - & - \\
\hline 23 & Epizonarene & 3.13 & 1495 & 0.08 & 1495 & 1.17 & 1495 & - & - \\
\hline 24 & Zonarene & 0.81 & 1530 & 0.13 & 1530 & 1.37 & - & 0.16 & 1530 \\
\hline 25 & $\begin{array}{l}\text { Citronellyl } \\
\text { butanoate }\end{array}$ & 0.18 & 1536 & 0.16 & 1536 & 1.70 & - & 0.16 & 1535 \\
\hline 26 & $\begin{array}{c}\text { Geranyl } \\
\text { butanoate }\end{array}$ & 0.43 & 1563 & 2.36 & 1563 & 2.12 & 1563 & 0.08 & 1563 \\
\hline 27 & $\begin{array}{l}\text { 2-Phenyl ethyl } \\
\text { tiglate }\end{array}$ & 4.15 & 1589 & 0.05 & 1588 & - & - & - & - \\
\hline 28 & $\alpha$-Muurolol & 1.72 & 1654 & tr. & 1654 & 0.23 & 1655 & tr. & 1654 \\
\hline 29 & $\begin{array}{l}\text { (e)-Citronellyl } \\
\text { tiglate }\end{array}$ & 0.90 & 1676 & 0.09 & 1676 & 1.07 & 1676 & 0.10 & 1675 \\
\hline 30 & Geranyl tiglate & 4.37 & 1713 & 0.06 & 1712 & 1.11 & 1712 & 0.08 & 1711 \\
\hline
\end{tabular}

tr. - trace $(<0.05 \%)$, RI - retention indices on VF - $5 \mathrm{~ms}$ capillary column, [\%] ${ }^{*}$ - compounds concentration in a sample, (-) - was not found

Table 2 presents the major components of examined Pelargonium spp. EO in comparison with available literature.

The main components of essential oil from indoor cultivation of $P$. graveolens, commercial essential oils from $P$. graveolens, $P$. odoratissimum and $P$. roseum in comparison with literature

\begin{tabular}{|c|c|c|c|c|c|c|c|c|}
\hline \multirow{2}{*}{ Source } & \multicolumn{8}{|c|}{ Component [\%] } \\
\hline & $\mathbf{1}^{*}$ & $2^{*}$ & $3^{*}$ & $4^{*}$ & $5^{*}$ & $6^{*}$ & $7^{*}$ & $8^{*}$ \\
\hline $\begin{array}{c}\text { Indoor } \\
P . \text { graveolens }\end{array}$ & 26.62 & 22.92 & 6.37 & 0.10 & 3.39 & 0.24 & tr. & - \\
\hline P. graveolens & 22.28 & 15.50 & 5.59 & 9.27 & - & 0.25 & 1.67 & 0.59 \\
\hline$[12,13,17,18,27,31,32]$ & $21-37.5$ & $6.0-26.8$ & $5.2-13$ & $0.08-0.2$ & $0.18-6.3$ & $0.3-8.7$ & $6.9-13.24$ & $1-6.22$ \\
\hline P. odoratissimum & 29.77 & 6.51 & 2.45 & 0.15 & 3.34 & 0.16 & 9.22 & 1.43 \\
\hline [25] & 8.99 & 12.69 & - & - & - & - & - & - \\
\hline P. roseum & 44.62 & 10.73 & 5.39 & 0.35 & 0.89 & 0.09 & 14.42 & 2.37 \\
\hline [24] & 28.96 & 18.53 & 5.72 & 0.68 & 4.22 & - & - & - \\
\hline
\end{tabular}

tr. - trace $(<0.05 \%),(-)$ - was not found, $\mathbf{1}^{*}$ - Citronellol, $\mathbf{2}^{*}$ - Geraniol, $\mathbf{3}^{*}$ - Linalool, $\mathbf{4}^{*}$ - Limonene, $\mathbf{5}^{*}$ - Isomethone, $\mathbf{6}^{*}$ - Neral, $\mathbf{7}^{*}$ - Citronellyl $\mathbf{8}^{*}$ - formate, $\mathbf{9}^{*}$ - Geranyl formate

\section{Phytochemical similarity of studied essential oils}

The gas chromatographic - mass spectral analysis of the volatile oils revealed significant differences in the number and the type of the identified volatile compounds. It is most likely due to the environmental conditions studied plants had grown in.

The gas chromatographic - mass spectral analysis of the volatile oils was a base for building a dendrogram of phytochemical similarity of all four pelargonium essential oils components with concentrations bigger than the reported limit of quantification (Fig. 1). Two groups of points can be observed in the graph. It can be noted that oils from $P$. odoratissimum and $P$. roseum make separate group that represents the relationship of biggest similarity in their oils compositions. The second group represents commercial extracts from $P$. graveolens and the one distilled from $P$. graveolens from indoor cultivar. 
Compositions of these oils were also similar to each other, but in somewhat lower degree than in the first group.

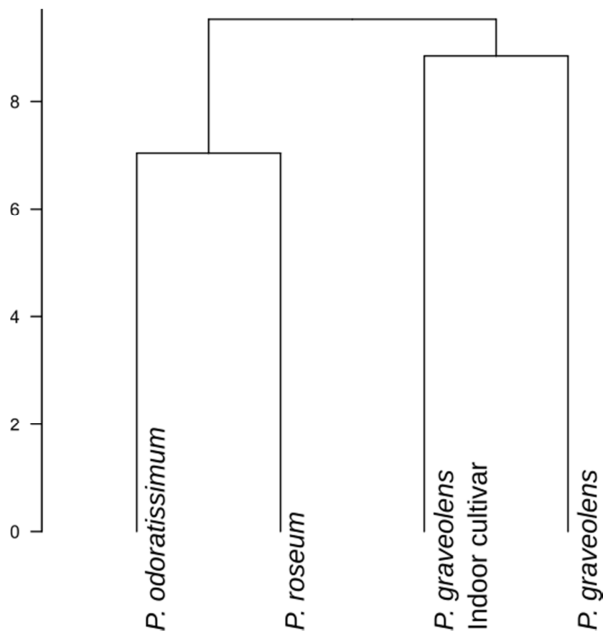

Fig. 1. Dendrogram of phytochemical similarity of commercial essential oils of $P$. graveolens, $P$. odoratissimum, $P$. roseum and indoor cultivar of $P$. graveolens

This dendrogram shows that essential oils from $P$. odoratissimum and $P$. roseum make separate group that represents the similarities in their chemical compositions. The second group contains commercial oils from $P$. graveolens as well as oil distilled from $P$. graveolens from indoor cultivar which means that despite their different starting materials, their compositions are alike.

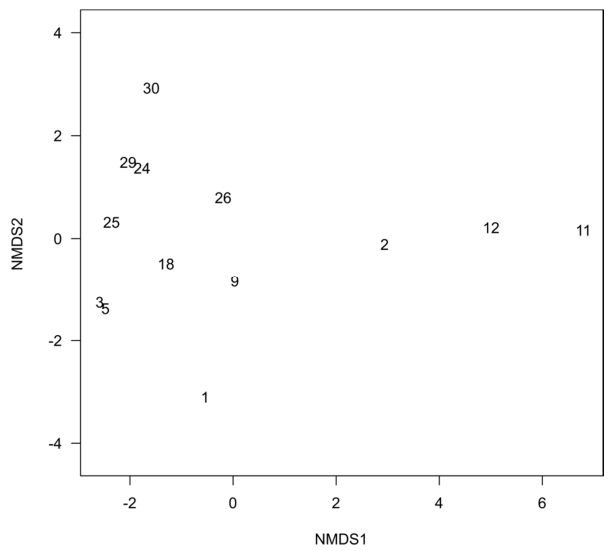

Fig. 2. MDS representation of the clr transformed oil's concentration in the studied pelargoniums essential oils

A similarity between relative compounds' concentration in the plants studied was assessed using nonmetric multidimensional scaling (MDS) method (Fig. 2) [28, 29]. 
The dissimilarity matrix was calculated for points representing clr transformed concentrations of individual compounds in the plants studied. In computation function "metaMDS" from "vegan" library was used [30]. A similarity between content of compound pairs 3,5 (cis-rose oxide, menthone) and 24, 29 (zonarene, (e)-citronellyl tiglate) in all studied essential oils is observed. The first pair $(3,5)$ belongs to the monoterpene group, while the second pair $(24,29)$ refers to the sesquiterpenes. The relative content of other compounds in plants are different from each other.

In Figure 2 MDS representation of the clr transformed oil's concentration is shown. Similarities in two pairs can be observed. First pair $(3,5)$ belongs to the monoterpene group, while the second pair $(24,29)$ refers to the sesquiterpenes. The relative content of other compounds in studied essential oils are different from each other.

\section{Discussion}

The literature report (Table 2) that oxygenated monoterpenes constitute the main group in every obtained essential oil (e.g. citronellol, geraniol, linalool or citronellyl formate) [5, 11, 19]. Comparing the available data (Table 2), all the studies show that for $P$. graveolens essential oil, citronellol is present in the most significant amount, reaching $37.5 \%$ of the total oil of the plant growing in Tajikistan in Sharopov et al. [20] research. Second major component was geraniol, of which Pelargonium from Himalayan region of India, that as explored [31] contained $26.8 \%$ of the total oil. A search of the literature reveals that beside the region of plant growth, all essential oils from $P$. graveolens contain a diverse range of compounds, nevertheless, in every single one, geraniol and citronellol are present in the most significant fraction of the total oil. Important compounds are also linalool and citronellyl formate that give the fresh citrusy-floral flavour to the EO. There is not much available data about chemical composition of $P$. odoratissimum and P. roseum. However, the data show that in Tabari and Youssefi [24], in examined essential oil form $P$. roseum, major constituents were $\beta$-citronellol $(28.96 \%)$, geraniol $(18.53 \%)$ and linalool $(5.72 \%)$. These results are very different from this investigation, where the amount of citronellol equaled $44.62 \%$, geraniol $10.73 \%$ and linalool $5.39 \%$, while another compound citronellyl formate was detected in a number of $14.42 \%$. It cannot be assured if it is due to the starting material properties or chemical reactions occurring in stored product. Main components found in P. odoratissimum [32] were geraniol (12.69\%) and citronellol $(8,99 \%)$. In present study these two compounds were also detected in the biggest amount, but in the opposite order (citronellol $29.77 \%$ and geraniol $6.51 \%$ ). Of all the examined essential oil in this research and from the available literature, the one of $P$. graveolens indoor cultivar has the closest $\mathrm{C}: \mathrm{G}$ ratio (1.16) which makes it a very valuable product. C:G of the commercial $P$. odoratissimum and $P$. roseum essential oils from this study equals more than 4 which makes them less valuable for the industry. Data from gas chromatography - mass spectrometry shows that composition of the studied essential oils vary in concentration of major constituents and also contain a different total number of compounds where the highest was determined in commercial EO of $P$. odoratissimum. What should be highlight is the fact that due to the relationships of chemicals from the same structural group, they can be easily convert into each other by oxidation, isomerization, cyclization, or dehydrogenation reactions, e.g. geraniol into citronellol, that is why the age of starting material plays a significant role in this aspect. 


\section{Conclusions}

Studied essential oils form Pelargonium genus are mixtures of different amount of chemical components. Every EO has its own unique composition, but all of them are highly similar to one another. However, it is important to remember that due to different environmental conditions, such as rainfall, soil fertility or light intensity, derived essential oils vary in composition. That results in market value of studied mixtures. Because of the fact that cosmetic and perfume industry seek for standardized oils, it is essential to gain the knowledge what cultivation conditions would be the best for this purpose. This issue is going to be the subject of next studies.

\section{References}

[1] Dorman HJD, Deans SG. Antimicrobial agents from plants: antibacterial activity of plant volatile oils. J Appl Microbiol. 2000;88: 308-16. DOI: 10.1046/j.1365-2672.2000.00969.x.

[2] Dorman HJD, Deans SG. Chemical composition, antimicrobial and in vitro antioxidant properties of Monarda citriodora var. Citriodora, Myristica fragrans, Origanum vulgare ssp. Hirtum, Pelargonium sp. and Thymus zygis oils. J Essent Oil Res. 2004;16:145-50. DOI: 10.1080/10412905.2004.9698679.

[3] Hsouna AB, Hamdi N. Phytochemical composition and antimicrobial activities of the essential oils and organic extracts from pelargonium graveolens growing in Tunisia. Lipids Health Dis. 2012;11:167. DOI: 10.1186/1476-511X-11-167.

[4] Cerempei A, Muresan EI, Cimpoesu N. Biomaterials with controlled release of geranium essential oil. J Essent Oil Res. 2014;26:267-73. DOI: 10.1080/10412905.2014.910711.

[5] Tongnuanchan P, Benjakul S. Essential oils: extraction, bioactivities, and their uses for food preservation. J Food Sci. 2014;79:1231-49. DOI: 10.1111/1750-3841.12492.

[6] Iancu C, Cioanca O, Hancianu M, Mircea C. Dried extracts and essential oils of some Pelargonium species: chemical and biological assessment. Indian J Pharm Edu Res. 2017;51(3):421-4. DOI: 10.5530/ijper.51.3s.60.

[7] ISO 9235:1997. Aromatic natural raw materials.

[8] Maurya S, Kushwaha AK, Singh G. Biological significance of spicy essential oils. Adv Nat Sci. 2013;6(4):84-95. DOI: 10.3968/j.ans.1715787020130604.1638.

[9] Turek C, Stintzing FC. Stability of essential oils: A review. Com Rev Food Sci Food Safety. 2013;12:40-53. DOI: 10.1111/1541-4337.12006.

[10] Andrade MA, Cardos MG, Batista LR, Freire JM, Nelson DL. Antimicrobial activity and chemical composition of essential oil of Pelargonium odoratissimum. Rev Bras Farm. 2011;21:47-52. DOI: 10.1590/S0102-695X2011005000009.

[11] Lalli JYY, Viljoen AM, Hüsnü K, Baser C, Demirci B, Özek T. The essential oil composition and chemotaxonomical appraisal of South African Pelargoniums (Geraniaceae). J Essent Oil Res. 2006;18:89-105. DOI: 10.1080/10412905.2006.12067128.

[12] Dyubeni L, Mayekiso B, Magwa ML. A comparative study on essential oil yield and composition of rose-scented geranium (P. c. v. Rose) commercially grown on three different sites of the Amathole region in the Eastern Cape, South Africa. Afric J Agric Res. 2012;7(43):5842-8. DOI: 10.5897/AJAR11.2441.

[13] Blerot B, Baudino S, Prunier C, Demarne F, Toulemonde B, Caissard JC. Botany, agronomy and biotechnology of Pelargonium used for essential oil production. Phytochem Rev. 2016;15:935-60. DOI: 10.1007/s11101-015-9441-1.

[14] Ravindra NS, Kulkarni RN, Gayathri MC, Ramesh S. Somaclonal variation for some morphological traits, herb yield, essential oil content and essential oil composition in an Indian cultivar of rose-scented geranium. Plant Breeding. 2004;123:84-6. DOI: 10.1046/j.1439-0523.2003.00943.

[15] Araya HT, Soundy P, Steyn JM, Teubes C, Learmonth RA, Mojela N. Response of herbage yield, essential oil yield and composition of South African Rose-Scented Geranium (Pelargonium sp.) to conventional and organic nitrogen. J. Essent Oil Res. 2006;18:111-5.

[16] Juliani HR, Koroch A, Simon JE, Hitimana N, Daka A, Ranarivelo L, et al. Quality of geranium oils (Pelargonium species): Case studies in Southern and Eastern Africa. J Essent Oil Res. 2006;18:116-21. DOI: 10.1080/10412905.2006.12067131. 
[17] Verma RS, Verma R K, Yadav AK, Chauhan A. Changes in the essential oil composition of rose-scented geranium (Pelargonium graveolens L'Herit. ex Ait.) due to date of transplanting under hill conditions of Uttarakhand. Ind J Nat Prod Res. 2010;1:367-70.

[18] Rajeswara Rao BR, Kaul PN, Mallavarapus GR, Ramesh S. Effect of seasonal climatic changes on biomass yield and terpenoid composition of rose-scented geranium (Pelargonium species). Biochem Syst Ecol. 1996;24(7/8):627-35. DOI: 10.1016/S0305-1978(96)00071-3.

[19] Džamić A, Soković MD, Ristić MS, Grujić SM, Mileski KS, Marin PD. Chemical composition, antifungal and antioxidant activity of Pelargonium graveolens essential oil. J Appl Pharm Sci. 2014;4:001-005. DOI: 10.7324/JAPS.2014.40301.

[20] Sharopov FS, Zhang H, Setzer WN. Composition of geranium (Pelargonium graveolens) essential oil from Tajikistan. Am J Essent Oil Nat Prod. 2014;2:13-6.

[21] Bigos M, Wasiela M, Kalemba D, Sienkiewicz M. Antimicrobial activity of geranium oil against clinical strains of Staphylococcus aureus. Molecules. 2012;17:10276-91. DOI: 10.3390/molecules 170910276.

[22] Nejad AR, Ismaili A. Changes in growth, essential oil yield and composition of geranium (Pelargonium graveolens L.) as affected by growing media. J Sci Food Agric. 2013;94:905-10. DOI: 10.1002/jsfa.6334.

[23] Ionela-Carmen G, Ielciu I, Crisan G, Tamas M. Histoanatomical studies on the vegetative and reproductive organs of Pelargonium roseum willd (Geraniaceae). Hosp and Medicinal Plants. XXV. Printing House Academicpres, Cluj-Napoca; 2017.

[24] Tabari MA, Youssefi MR. In vitro and in vivo evaluations of Pelargonium roseum essential oil activity against Trichomonas gallinae. Avicenna J Phytomed. 2018;8:136-42. DOI: 10.22038/AJP.2017.20763.1788.

[25] Romitelli I, Martins MBG. Comparison of leaf morphology and anatomy among Malva sylvestris ("gerânioaromático"), Pelargonium graveolens ("falsa-malva") and Pelargonium odoratissimum ("gerânio-decheiro"). Rev Bras Plantas Med. 2013;15(1):91-7. DOI: 10.1590/S1516-05722013000100013.

[26] Aitchison J. The Statistical Analysis of Compositional Data. New Yersey. Caldwell: The Blackburn Press; 2003. https://www.jstor.org/stable/2345821.

[27] R Development Core Team. R: A language and environment for statistical computing. Vienna. Austria: $\mathrm{R}$ foundation for Statistical Computing; 2018. http://www.R-project.org.

[28] Borg I, Groenen PJF, Mair P. Applied Multidimensional Scaling. Springer Briefs in Statistics. Berlin Heidelberg: Springer; 2013. DOI: 10.1007/978-3-642-31848-1;2013.

[29] Ding CS. Fundamentals of Applied Multidimensional Scaling for Educational and Psychological Research. Cham: Springer International Publishing; 2018. DOI: 10.1007/978-3-319-78172-3.

[30] Oksanen J, Blanchet FG, Friendly M, Kindt R, Legendre P, McGlinn D, et. al. ,vegan: Community Ecology Package. R package version 2.5-5". https://CRAN.R-project.org/package=vegan; 2019.

[31] Rana VS, Juyal JP, Blazquez MA. Chemical constituents of essential oil of Pelargonium graveolens leaves. Int J Aromather. 2002;12:216-18. DOI: 10.1016/S0962-4562(03)00003-1.

[32] Pombo LM, Matulevich J, Borrego P. Composición química y actividad antimicrobiana del aceite esencial de Pelargonium odoratissimum (L) L'Hér (GERANIACEAE). Congress Abstracts Book, II International Congress on Integrative Medicine. 2015. DOI: 10.18359/rfcb.1856;2015. 